Note

\section{Essential Structures in the Complementary DNA Origin of Bacteriophage G4}

\author{
Hiroshi SaKaI, Tohru Komano \\ and G. Nigel Godson* \\ Laboratory of Biochemistry, \\ Depdrtment of Agricultural Chemistry, \\ Kyoto University, \\ Kyoto 606, Japan \\ * Department of Biochemistry, \\ New York University School of Medicine, \\ 550 First Avenue, New York, \\ NY 10016, U.S.A.
}

Received July 23, 1984

G4 is a bacteriophage closely related to $\phi \mathrm{X} 174^{19}$ with single-stranded circular DNA of 5577 bases. The priming system for the initiation of synthesizing the complementary DNA strand of G4 is distinct from that of $\phi \mathrm{X} 174 .^{2,3)}$ With phage $\phi \mathrm{X} 174$, the priming system is rather complex and contains eight proteins. With phage $\mathrm{G} 4$, the single- strand-binding $(s s b)$ protein and the $d n a G$ protein (primase) of E. coli are essential to synthesize the primer RNA molecules at the complementary origin of G4 (Goric) which contains three stems and loops I, II, and III (Fig. 1). The 274 base-pair AluI fragment from G4 RF DNA, which contains the entire Gori $_{\mathrm{c}}$ region in the intergenic space between the $\mathrm{F}$ and $\mathrm{G}$ genes, ${ }^{4)}$ was cloned in a correct or functional orientation to a filamentous phage vector, R199. ${ }^{5)}$ The chimeric phage R199/G4 carries the Goric region inserted at the $E c o$ RI site in such a way that $E c o$ RI sites were restored at both the ends of the Goric segment. The genomic DNA of R199/G4 carries a unique AvalI site at the foot of stem III in the Gori $_{\mathrm{c}}$ region.

A 10 base-pair BamHI linker (CCGGATCCGG) was inserted at the filled-in AvaII-cleaved site of R199/G4 RF DNA followed by transfection to E. coli JM103. ${ }^{6}$ The resulting insertion mutant was named R199/G4-Bam4122 (Fig. 1). Another insertion mutant, R199/G4-Eco16, was constructed by inserting an 8 base-pair EcoRI linker (GGAATTCC) in the same manner. Actual DNA sequences in the altered region of each insertion mutant were confirmed by the Maxam-Gilbert sequencing method (Fig. 2(a), (b), and (c)). With the mutant Bam4122, the spacing between the stems II and III is 13 bases longer than that of the wild type Gori (Fig. 1). The mutant Ecol6 carries two structural alterations (Fig. 1). First, the spacing between stems II and III is 10 base-pair longer than that of the wild type Gori $_{\mathrm{c}}$. The G residue adjacent to the

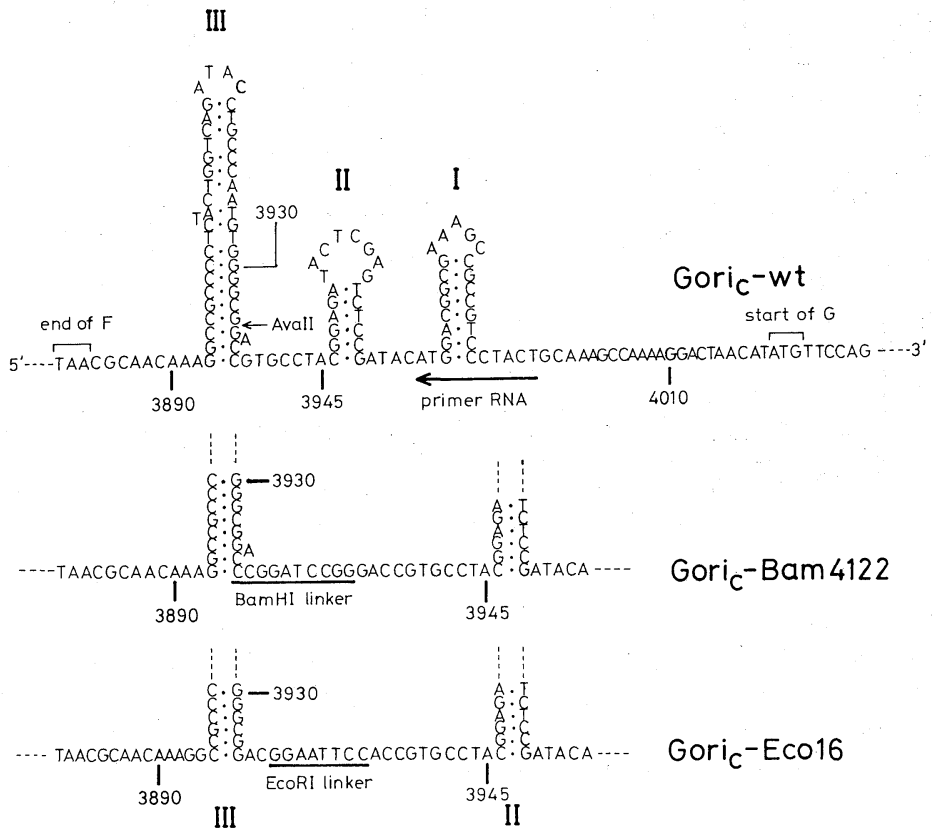

Fig. 1. Schematic Representation of the Potential Secondary Structures of Gori $_{\mathfrak{c}}$ wild type, Bam4122, and Eco16.

Numerals 3890,3930 and 4010 indicate the nucleotide numbers on the G4 genome. ${ }^{10)}$ Base sequences involving a part of the stems and loops II and III are shown for Bam4122 and Eco16. 


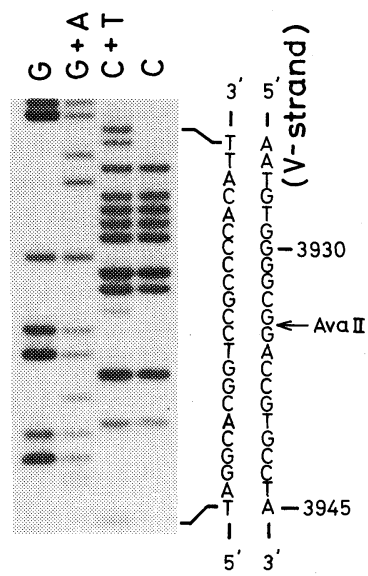

(a)

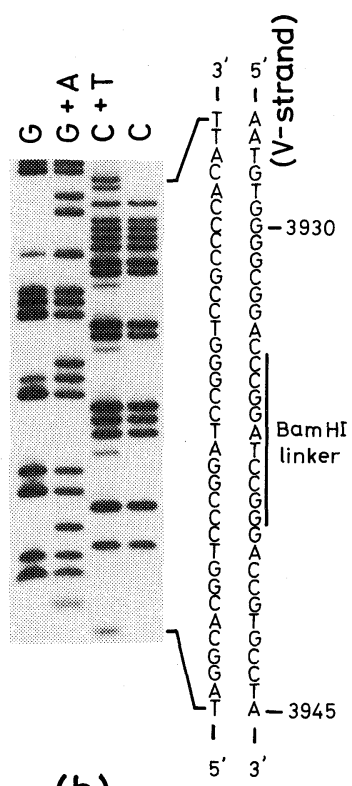

(b)

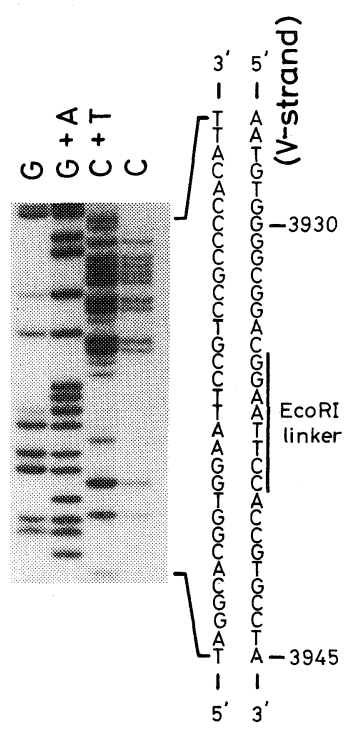

(c)

FIG. 2. DNA Sequences of Altered Tracts in the Gori $i_{\mathrm{c}}$ Region of R199/G4 wild type, Bam4122, and Eco16.

Base sequences of the viral strand $(=\mathrm{V}$-strand) are given to the right of those of the complementary strand determined on the gel. Numerals 3930 and 3945 indicate the nucleotide numbers on the G4 genome. ${ }^{10)}$ (a)

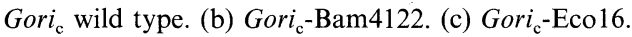

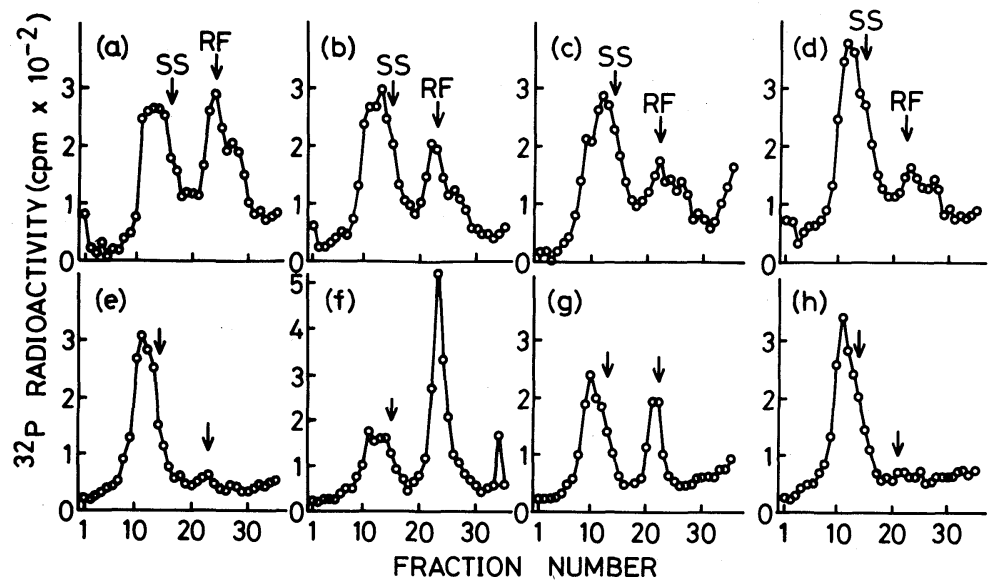

FIG. 3. Formation of the Parental RF DNA in the Presence and Absence of Rifampicin.

Sedimentation is from right to left. Arrows with SS and RF indicate the location of single-stranded circular and replicative form DNAs as internal markers, respectively. In experiments (a), (b), (c), and (d), E. coli JM103 is infected with ${ }^{32}$ P-labeled phages R199, R199/G4, R199/G4-Bam4122, and R199/G4-Eco16 in the absence of rifampicin, respectively. In experiments (e), (f), (g), and (h), the bacterium is infected with ${ }^{32} \mathrm{P}$-labeled phages $\mathrm{R} 199$, R199/G4-Bam 4122 and R199/G4-Ecol6 in the presence of $200 \mu \mathrm{g} / \mathrm{ml}$ rifampicin, respectively.

right-hand end of the EcoRI linker is missing for unknown reasons. Second, the presence of a $\mathrm{G}$ residue at the left end of the inserted EcoRI linker disrupts the lowermost GC base pair in stem III. Because of the unpaired A at 3936 and of the two mismatched Gs at 3894 and at 3938, the mutant Eco 16 possibly contains a stem III two base pairs shorter than that of wild type Gori. . In other words the mutant Ecol6 may contain aberrant structures at the foot of stem III.

Phages of R199, R199/G4, R199/G4-Bam4122, and 
R199/G4-Eco16 were labeled with ${ }^{32}$ P-phosphoric acid. The Gori $i_{\mathrm{c}}$ activity was estimated by measuring the extent of parental RF formation upon infection by the phages of E. coli JM103 in the presence of $200 \mu \mathrm{g} / \mathrm{ml}$ rifampicin. Experimental procedures for phage preparation and infection have been described. ${ }^{7,8)}$ The phage-bacterium complexes were killed by adding an equal volume of $2 \mathrm{X}$ poison buffer $\left(20 \mathrm{~mm} \quad \mathrm{NaN}_{3} / 20 \mathrm{~mm} \mathrm{KCN} / 2 \mathrm{~mm} \quad\right.$ EDTA/20 mM Tris- $\mathrm{HCl}(\mathrm{pH} 8.0)$ ), washed three times with $1 \mathrm{X}$ poison buffer $\left(10 \mathrm{~mm} \quad \mathrm{NaN}_{3} / 10 \mathrm{~mm} \quad \mathrm{KCN} / 1 \mathrm{~mm} \quad\right.$ EDTA $/ 10 \mathrm{~mm}$ Tris- $\mathrm{HCl}(\mathrm{pH} 8.0)$ ) and lysed with $6 \mathrm{mg} / \mathrm{ml}$ lysozyme and $1 \%$ Sarkosyl. The crude lysates were layered over 5 to $20 \%$ sucrose gradients and spun at $25,000 \mathrm{rpm}$ for $15 \mathrm{hr}$ at $4^{\circ} \mathrm{C}$ in an RPS-40T rotor of a Hitachi preparative ultracentrifuge 65P. After dropwise fractionation, the radioactivity in each fraction was measured in a liquid scintillation counter.

In the absence of rifampicin, the ori $_{\mathrm{c}}$ of R199 itself and possibly the Gori $_{\text {c }}$ were functional (Fig. 3(a) and (b)). While the ori $i_{\mathrm{c}}$ activity of R199 was inhibited in the presence of rifampicin, the Gori $_{\mathrm{c}}$ carried by R199/G4 was active even in the presence of the drug (Fig. 3(e) and (f)). Thus, the Gori $_{\mathrm{c}}$ function can be detected as a rifampicin-insensitive single-strand initiation ( $s s i$ ) activity. The insertion mutant R199/G4-Bam4122 had diminished, but not completely abolished Gori $i_{\mathrm{c}}$ activity (Fig. 3(c) and (g)). The insertion mutant R199/G4-Eco16 had almost no detectable Gori $i_{\text {c }}$ activity (Fig. 3(d) and (h)).

According to these experimental results, it is conceivable that the GC-rich tract centered in the AvalI site in the Gori $i_{\mathrm{c}}$ cartridge is at least a part of the Gori $i_{\mathrm{c}}$ determinant sequences. It is assumed that the potential secondary structures shown in Fig. 1 play essential roles in the Gori $i_{\mathrm{c}}$ directed priming events. ${ }^{4)}$ It is conceivable that the 7 base space between stems II and III is essential for the normal expression of Gori $_{\mathrm{c}}$ function at the wild type level. It is also conceivable that in addition to the presence of the proper spacing between the stems II and III, the presence of the specific structure formed by the two GC base pairs at the bottom of stem III is essential to the functional Goric activity. This idea is quite consistent with the in vitro experimental results obtained with phage $\phi \mathrm{K}$, which is closely related to phage $\mathrm{G} 4 .{ }^{9}$ ) Phage $\phi \mathrm{K}$ requires the same priming proteins as $\mathrm{G} 4$ for its ori $i_{\mathrm{c}}$ to be functional. Sims and Benz demonstrated that the $E$. coli primase molecule binds to domains in the $\phi \mathrm{K}$ ori $i_{\mathrm{c}}$ tract involving the bottom regions of and the spacing regions between stem structures in the functional or $i_{\mathrm{c}}$ priming complex. ${ }^{9}$ )

\section{REFERENCES}

1) G. N. Godson, Virology, 58, 272 (1974).

2) A. Kornberg, "1982 Supplement to DNA Replication," W. H. Freeman and Co., San Francisco, 1982, p. S101.

3) M. M. Stayton and A. Kornberg, J. Biol. Chem., 258, 13205 (1983).

4) G. N. Godson, J. C. Fiddes, B. G. Barrell and F. Sanger, "The Single-stranded DNA Phages," ed. by D. T. Denhardt, D. Dressler and D. S. Ray, Cold Spring Harbor Laboratory, New York, 1978, p. 51.

5) G. N. Godson, Abstracts of Papers, XIth International Congress of Biochemistry, Toronto, Canada, 1979, p. 7.

6) N. D. Zinder and J. D. Boeke, Gene, 19, 1 (1982).

7) D. S. Ray and R. W. Schekman, Biochim. Biophys. Acta, 179, 398 (1969).

8) A. B. Forsheit and D. S. Ray, Virology, 43, 647 (1971).

9) J. Sims and E. W. Benz, Proc. Natl. Acad. Sci. U.S.A., 77, 900 (1980).

10) G. N. Godson, B. G. Barrell, R. Staden and J. C. Fiddes, Nature, 276, 236 (1978). 